\title{
ANALISIS KESALAHAN SISWA KELAS XI PADA MATERI TRIGONOMETRI
}

\author{
Ardy Fauzi Rachman', Saripudin ${ }^{2}$ \\ ${ }^{1,2}$ IKIP Siliwangi, Jl. Terusan Jendral Sudirman, Cimahi tengah, Kota Cimahi, Jawa Barat \\ ardyfauzirachman@gmail.com
}

\begin{abstract}
This study aims to determine students' mistakes in solving trigonometric problems and their causal factors. This type of research is descriptive qualitative. The subjects of this study were 12 students of class XI MIPA 3 in MAN Cimahi City. Data collection techniques using tests and interviews. Data analysis techniques through three stages, namely data reduction, data presentation, as well as data verification and conclusion drawing. The analytical framework used is based on indicators of errors by hadar, namely: errors in data usage, errors in language interpretation, errors in drawing conclusions, errors in the use of theorems or definitions, resolutions not re-examined, and errors in calculations. The results showed there were student errors in completing trigonometric questions, including: (1) errors in data usage of $17.02 \%$, (2) language interpretation errors of $19.15 \%,(3)$ errors in drawing conclusions of $6.38 \%$ (4) errors of theorem or definition of $17.02 \%$, (5) errors were not re-examined by $29.79 \%$, and (6) errors in calculations were $10.64 \%$. Factors that cause student errors are generally caused by students not understanding the purpose of the problem and interpreting real problems into mathematical models.
\end{abstract}

Keywords: Analysis of concept errors, Trigonometry

\begin{abstract}
Abstrak
Penelitian ini bertujuan untuk mengetahui kesalahan siswa dalam menyelesaikan soal trigonometri serta faktor penyebabnya. Jenis penelitian ini adalah deskriptif kualitatif. Subjek penelitian ini adalah 12 siswa kelas XI MIPA 3 di MAN Kota Cimahi. Teknik pengumpulan data menggunakan tes dan wawancara. Teknik analisis data melalui tiga tahapan yaitu reduksi data, penyajian data, serta verivikasi data dan penarikan kesimpulan. Kerangka analisis yang digunakan berdasarkan indikator kesalahan oleh hadar, yaitu: kesalahan dalam penggunaan data, kesalahan dalam penafsiran bahasa, kesalahan dalam penarikan kesimpulan, kesalahan dalam penggunaan teorema atau definisi, penyelesaian tidak diperiksa kembali, dan kesalahan dalam perhitungan. Hasil penelitian menunjukan terdapat kesalahan siswa dalam menyelesaikan soa trigonometri, meliputi: (1) kesalahan penggunaan data sebesar 17.02\%, (2) kesalahan penafsiran bahasa sebesar 19.15\%,(3) kesalahan dalam penarikan kesimpulan sebesar sebesar $6.38 \%$ (4) kesalahan penggunaan teorema atau definisi sebesar $17.02 \%$, (5) kesalahan tidak diperiksa kembali sebesar 29.79\%, dan (6) kesalahan dalam perhitungan sebesar $10.64 \%$. Faktor penyebab kesalahan siswa pada umumnya disebabkan siswa tidak memahami maksud dari soal serta menafsirkan permasalahan nyata kedalam model matematika.
\end{abstract}

Kata kunci: Analisis kesalahan konsep, Trigonometri

\section{PENDAHULUAN}

Pendidikan adalah kegiatan belajar mengajar yang wajib didapatkan setiap individu baik secara formal maupun informal menurut Chotimah (2019). Pendidikan diberikan kepada anak dengan harapan supaya kelas menjadi anak bangsa yang berkualitas (suyadi, 2011). Salah satu mata pelajaran wajib pada pendidikan formal yang dipelajari dari jenjang Sekolah Dasar (SD) sampai Sekolah Menengah Atas (SMA) atau sederajat adalah matematika. Matematika juga memegang peran penting dalam perkembangan ilmu pengetahuan menurut Fitriani (Arafani, E., Herlina, E., Zhanty, L, 2019). Matematika digunakan untuk menyederhanakan masalah nyata yang setiap harinya semakin kompleks. Matematika digunakan juga untuk teknologi seperti komputer, kalkulator, handphone, dan lain-lain. Hal tersebut sesuai Hal tersebut sesuai yang dikemukakan Soewandi (Suhartini, T, (2017) bahwa matematika adalah suatu aktivitas manusia. Masalahnya matematika dianggap pelajaran yang sukar (Hidayat, 2019; Nurhayati, 2019; Bernard, 2019). Hal tersebut kontradiktif dengan Andayani (2019) 
bahwa matematika merupakan ilmu dasar yang mempunyai peranan penting dalam perkembangan ilmu dan teknologi. Maka dari itu pelajaran matematika sangat penting untuk dipelajari (Andriansyah, R., Zanthy, L, 2019; Isnaeni, 2019; Wiliawanto, 2019). Menurut Morgan, dkk (Baharuddin \& Wahyudi, 2008) belajar adalah perubahan perilaku dalam hal pemahaman, persepsi, perilaku, atau gabungan dari semuanya yang relatif tetapDalam kaitan dengan matematika, pembelajaran matematika seharusnya tidak mengarahkan siswa untuk menghafal rumus. Menurut Andriani, T., Suastika, K., Sesanti, N (2019) menyatakan bahwa matematika selalu identik dengan konsep dan siswa akan selalu dituntut untuk memahami konsep-konsep yang ada pada matematika. Menurut Cucu (2010) menyatakan bahwa konsep adalah suatu gagasan yang dibangun atas memperhatikan sifat-sifat yang persis dari sekumpulan paradigma yang sesuai. Dengan demikian, pendidik mengarahkan siswa untuk menguasai konsep pada mata pelajaran matematika. Hal tersebut sependapat dengan Zulkardi (2003:7) mengatakan bahwa pelajaran matematika menekankan kepada konsep.

Penguasaan konsep pada materi pelajaran matematika dapat digunakan untuk memecahkan masalah nyata. Dalam memecahkan masalah pada matematika diperlukan keterampilan seperti menafsirkan masalah menjadi model matematika, keterampilan berhitung, keteramapilan penguasaan konsep, dan lain-lain agar siswa dalam mengerjakan soal matematika tidak terjadi kesalahan. Terutama pada materi trigonometri. Menurut Kariadinata, R (2012) mengemukakan bahwa trigonometri adalah sebuah cabang matematika yang berhadapan dengan sudut segitiga dan fungsi trigonometrik, seperti sinus, kosinus, dan tangen yang membutuhkan proses berpikir (Bernard, 2019). Jenis-jenis kesalahan yang sering dilakukan oleh siswa dalam menyelesaikan soal-soal matematika menurut Rosita (Andriani, T., Suastika, K., Sesanti, N, 2019) antara lain kesalahan interpretasi bahasa, siswa sering keliru dalam menyatakan bahasa sehari-hari kedalam model matematika. Hal tersebut dikarenakan banyaknya simbol-simbol, grafik dan tabel sehingga membuat siswa melakukan kesalahan tersebut; kesalahan teknis, dalam aspek ini siswa sering melakukan kesalahan-kesalahan perhitungan atau komputasi dalam mengerjakan soal-soal; kesalahan konsep, seringkali siswa keliru dalam menentukan atau menerapkan rumus untuk menjawab suatu masalah. Siswa membuat kesalahan dalam pemakaian teorema dan rumus yang tidak sesuai dengan kondisi berlakunya rumus tersebut. Sedangkan berdasarkan hasil analisis kesalahan siswa menurut Mulyani, M., Muhtadi, D. (2019) menyimpulkan bahwa kurang cermat dalam menyelesaikan soal dan terlalu tergesa-gesa dalam mengerjakan, kesalahan berupa memilih strategi dalam menjabarkan masing-masing soal dengan rumus-rumus Trigonometri yang sudah dipelajari yang mengakibatkan perhitungan menjadi rumit sehingga bingung mengubah soal cerita kedalam gambar sketsa, lupa konsep dan rumus, kurang cermat dalam menyederhanakan, kesalahan dalam mengitung dan menyimpulkan hasil akhir. Sedangkan menurut Niasih (2019) menyatakan bahwa kurangnya penguasaan konsep, rendahnya keterampilan siswa dalam menarik kesimpulan, siswa kurang cermat dalam menyelesaikan soal, dan siswa menjawab tidak disertai alasan yang jelas.

Seperti halnya pembelajaran di MAN Kota Cimahi, didapatkan siswa yang masih kesukaran dalam memahami konsep yang diajarkan. Hal ini yang melahirkan soal yang diberjakan terjadi 
kesalahan (Rohaeti, 2019; Bernard, 2019). Kesalahan yang terlihat pada siswa salah satunya pada materi trigonometri, khususnya pada subab aturan sinus, aturan cosinus, luas segitiga yang membutuhkan pemahaman konsep dan ketelitian yang tinggi. Berdasarkan hasil wawancara kepada siswa kelas XI MIPA 3 MAN Kota Cimahi, ternyata siswa merasa kesulitan dalam mengerjakan soal trigonometri, karena tidak tahu memakai rumus yang benar dalam mengerjakan soal trigonometri.

Oleh karena itu, diperlukan analisis kesalahan siswa. Pengertian analisis kesalahan siswa menurut Adhim, B. \& Amin, S. (2019) adalah penyelidikan dari jenis dan letak kesalahan beserta faktor penyebanya. Maka dari itu penting untuk menganalisis kesalahan siswa terutama menyelesaikan soal trigonometri, agar siswa tidak mengulang kesalahan konsep yang berkesinambungan. Materi pada matematika merupakan pondasi awal untuk materi selanjutnya. Jika siswa tidak mampu memahami konsep matematika secara benar maka siswa tersebut akan kesulitan dalam memahami konsep matematika pada materi selanjutnya.

\section{METODE}

Penelitian ini merupakan penelitian deskriptif kualitatif. Menurut Nazir (2019) metode desriptif adalah suatu cara untuk meneliti suatu objek, suatu manusia, suatu pemikiran, suatu kelas peristiwa pada masa kini ataupun suatu set kondisi. Penelitian ini bertujuan untuk melihat letak kesalahan siswa pada konsep materi trigonometri dan faktor penyebab kesalahannya.. Subjek dalam penilitan ini ialah siswa kelas XI MIPA 3 MAN Kota Cimahi. Teknik pengumpulan data yang digunakan dalam penelitian ini adalah tes dan wawancara. Tes yang diberikan merupakan tes individu yang harus dikerjakan oleh siswa, setelah itu dilakukan wawancara pada beberapa siswa yang dipilih sesuai dengan kategori pada penelitian ini. Analisis data dalam penelitian ini menggunakan tahapan analisis menurut Sugiyono (2011) yaitu: (1) Reduksi Data; mereduksi data dengan cara menitikberatkan pada hal-hal yang penting. Dalam penelitian ini, reduksi data dilaukan dengan memilih hasil pekerjaan siswa yang melakukan kesalahan. Kemudian peneliti mengklasifikasikan kesalahan siswa menurut indikator kesalahan. Reduksi data dilakukan dengan tiga tahap yaitu: a) merekam hasil wawancara dan mencatat hasil wawancara tersebut, b) memeriksa catatan dengan mendengarkan ulang rekaman wawancara, c) hasil catatan ditulis berdasarkan informasi yang dibutuhkan. Penyajian data pada penelitian ini yaitu presentase kesalahan siswa menggunakan indikator menurut Hadar (2019) yaitu: kesalahan dalam penggunaan data (K1), kesalahan dalam penafsiran bahasa (K2), kesalahan dalam penarikan kesimpulan (K3), kesalahan dalam penggunaan teorema atau definisi (K4), penyelesaian tidak diperiksa kembali (K5), dan kesalahan dalam perhitungan (K6). (2) Penyajian Data; Dalam penelitian ini, data aka disajikan dalam bentuk diagram yang menampilkan presentase jenis kesalahan menurut indikator kesalahan, dan (3) penarikan kesimpulan; Data yang sudah analisis jenis kesalahannya kemudian akan ditarik kesinpulan.

\section{HASIL}

Penelitian ini dilaksanakan di kelas XI MIPA 3 MAN Kota Cimahi yang berjumah 12 siswa. Soal 
yang diuji cobakan pada subjek penelitian disertakan indikator capaian yang ditampilkan dalam tabel di bawah ini:

\section{Tabel 1.}

Kisi-Kisi Soal Materi Trigonometri

\begin{tabular}{|c|c|c|c|}
\hline Kompetensi Dasar & Pokok Bahasan & Indikator & Nomor soal \\
\hline \multirow{3}{*}{$\begin{array}{l}\text { Menjelaskan rasio } \\
\text { trigonometri (sinus, } \\
\text { cosinus, tangen, } \\
\text { cosecan, secan, dan } \\
\text { cotangen) pada } \\
\text { segitiga siku-siku }\end{array}$} & $\begin{array}{l}\text { Perbandingan } \\
\text { Trigonometri }\end{array}$ & Menemukan hubungan antar sudut & 3 \\
\hline & $\begin{array}{l}\text { Identitas } \\
\text { Trigonometri }\end{array}$ & $\begin{array}{l}\text { Mengamati dan mengidentifikasi } \\
\text { hubungan antara rasio trigonometri yang } \\
\text { membentuk identitas dasar trigonometri }\end{array}$ & 4 \\
\hline & $\begin{array}{l}\text { Identitas } \\
\text { Trigonometri }\end{array}$ & $\begin{array}{l}\text { Mengamati dan mengidentifikasi } \\
\text { hubungan antara rasio trigonometri yang } \\
\text { membentuk identitas dasar trigonometri }\end{array}$ & 6 \\
\hline \multirow{3}{*}{$\begin{array}{l}\text { Menjelaskan aturan } \\
\text { sinus dan cosinus }\end{array}$} & Luas Segitiga & $\begin{array}{l}\text { Menemukan aturan umum untuk } \\
\text { menghitung luas segitiga }\end{array}$ & 1 \\
\hline & Aturan Sinus & $\begin{array}{l}\text { Menyelesaikan masalah menggunakan } \\
\text { aturan sinus }\end{array}$ & 2 \\
\hline & Aturan cosinus & $\begin{array}{l}\text { Menyelesaikan masalah } \\
\text { menggunakan aturan cosinus }\end{array}$ & 5 \\
\hline
\end{tabular}

Berikut data hasil tes soal materi trigonometri yang disajikan pada Tabel 1.

Tabel 2.

Penskoran Soal Materi Trigonometri

\begin{tabular}{|c|c|c|c|c|c|c|c|}
\hline \multirow{2}{*}{ Kode Siswa } & \multicolumn{6}{|c|}{ Soal Nomor ke- } & \multirow{2}{*}{ Skor } \\
\hline & 1 & 2 & 3 & 4 & 5 & 6 & \\
\hline S01 & 15 & 5 & 0 & 10 & 0 & 10 & 57.14 \\
\hline S02 & 8 & 3 & 3 & 10 & 5 & 3 & 45.71 \\
\hline S03 & 5 & 10 & 0 & 3 & 0 & 0 & 25.71 \\
\hline S04 & 15 & 3 & 0 & 10 & 3 & 0 & 44.29 \\
\hline S05 & 5 & 3 & 3 & 10 & 0 & 3 & 34.29 \\
\hline S06 & 15 & 3 & 0 & 10 & 5 & 3 & 51.43 \\
\hline S07 & 10 & 3 & 0 & 10 & 0 & 0 & 32.86 \\
\hline S08 & 5 & 10 & 0 & 10 & 0 & 0 & 35.71 \\
\hline S09 & 5 & 10 & 0 & 10 & 0 & 0 & 35.71 \\
\hline S10 & 5 & 10 & 0 & 10 & 0 & 3 & 40.00 \\
\hline S11 & 5 & 10 & 0 & 10 & 0 & 3 & 40.00 \\
\hline S12 & 5 & 10 & 3 & 10 & 0 & 3 & 44.29 \\
\hline
\end{tabular}

Berdasarkan hasil dari data tersebut didapat informasi bahwa rata-rata dalam mengerjakan soal trigonometri adalah 40.6. Jadi kemampuan siswa kelas XI MIPA 3 MAN Kota cimahi dalam menyelesaikan soal trigonometri tergolong rendah. Terutama pada soal no 3 dengan indikator menemukan hubungan antar sudut. Berdasarkan hasil wawancara diperoleh faktor penyebabnya adalah siswa tidak paham dalam mengubah informasi pada soal kedalam bentuk model matematika. 


\section{Analisis kesalahan siswa berdasarkan indikator kesalahan}

\section{Tabel 3.}

Hasil tes siswa berdasarkan indikator kesalahan

\begin{tabular}{|c|c|c|c|c|c|c|}
\hline \multirow{2}{*}{ Kode Siswa } & \multicolumn{7}{|c|}{ Soal Nomor Ke- } \\
\cline { 2 - 7 } & $\mathbf{1}$ & $\mathbf{2}$ & $\mathbf{3}$ & $\mathbf{4}$ & $\mathbf{5}$ & $\mathbf{6}$ \\
\hline S01 & - & K1 & K4 & 0 & K2 & K6 \\
\hline S02 & K5 & K1 & K4 & - & K4 & K4 \\
\hline S03 & K5 & - & K6 & K5 & K2 & K5 \\
\hline S04 & K5 & K6 & K1 & - & K5 & K2 \\
\hline S05 & - & K2 & K1 & - & K6 & - \\
\hline S06 & K4 & - & K3 & - & K2 & K3 \\
\hline S07 & K5 & - & K4 & - & K4 & K5 \\
\hline S08 & K2 & - & K1 & - & K4 & K4 \\
\hline S09 & K5 & K5 & K4 & - & K5 & K5 \\
\hline S10 & - & K1 & K2 & - & K4 & K2 \\
\hline S11 & K3 & - & K2 & - & K1 & K1 \\
\hline S12 & K3 & K3 & K3 & K4 & - & K4 \\
\hline
\end{tabular}

Dari pengelompokan di atas dapat disimpulan bahwa yang tergolong kesalahan penggunaan data (K1) sebesar 17.02\%, kesalahan penafsiran bahasa (K2) sebesar 19.15\%, kesalahan dalam penarikan kesimpulan (K3) sebesar 6.38\%, kesalahan penggunaan teorema atau definisi (K4) sebesar $17.02 \%$, kesalahan tidak diperiksa kembali (K5) sebesar 29.79\%, dan kesalahan dalam perhitungan (K6) sebesar 10.64\%. Berdasarkan hasil tersebut dapat dibuat diagram sebagai berikut:

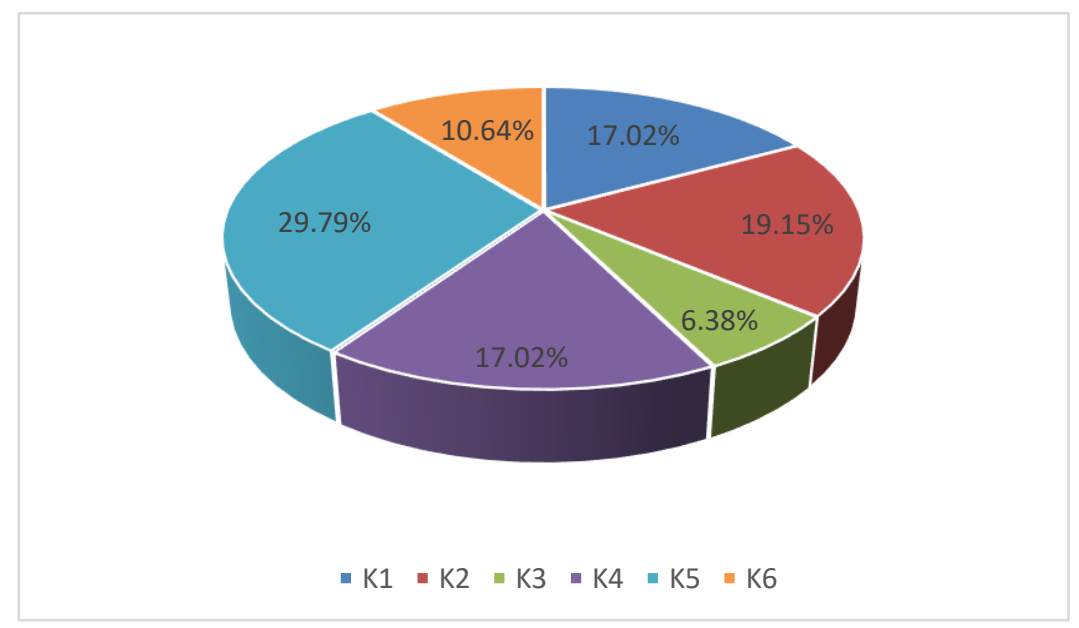

Gambar 1. Diagram presentase indikator kesalahan

Berdasarkan gambar 1 dapat diurutkan kesalahan siswa dari yang terbesar berturut-turut adalah kesalahan tidak diperiksa kembali (K5), kesalahan penafsiran bahasa (K2), kesalahan penggunaan data (K1), kesalahan penggunaan teorema atau definisi (K4), kesalahan dalam perhitungan (K6), dan kesalahan dalam penarikan kesimpulan (K3). Berdasarkan hasil wawancara didapatkan penyebab faktor kesalahan siswa yaitu sebagian siswa tidak bisa menuliskan informasi kedalam bentuk model matematika. Hal ini terjadi karena siswa tidak mamahami informasi dari soal tersebut. Selain itu, siswa 
membutuhkan waktu yang cukup untuk memahami kemudian menuliskan informasi dari soal. Sehingga siswa tergesa-tergesa dalam menyelesaikan soal yang mengakibatkan siswa tidak dapat menggunakan rencana yang tepat, tidak memeriksa kembali jawaban dikarenakan siswa sudah merasa yakin dengan jawaban awal, dan siswa tidak teliti dalam proses perhitungan.

Hasil penelitian ini sejalan dengan sejalan dengan penelitian yang dilakukan oleh Akbar, dkk (2018) yaitu kesalahan tidak diperiksa kembali bahwa siswa beranggapan tidak perlu melakukan pengecekan kembali jawaban karena meyakini jawaban awal sudah benar. Oleh karena itu, presentase kesalahan siswa yang paling tinggi adalah kesalahan tidak diperiksa kembali (K5) karena siswa sudah merasa yakin jawaban sudah benar. Kemudian presentase kesalahan siswa terendah yaitu kesalahan dalam penarikan kesimpulan (K3). Faktor penyebab kesalahannya yaitu siswa tergesa-gesa dalam menyelesaikan soal yang mengakibatkan siswa tidak membuat kesimpulan karena kehabisan waktu dalam pengerjaan soal. Hal tersebut sejalan dengan hasil penelitian Anwar (2019) bahwa faktor penyebab kesalahan yang dilakukan siswa yaitu siswa terburu-buru dalam menyelesaikan soal.

\section{KESIMPULAN}

Kesimpulan dan saran dari penelitian ini sebagai berikut. Berdasarkan kategori kesalahan menurut hadar dalam mengerjakan soal pada materi trigonometri diperoleh presentase kesalahan sebagai berikut: kesalahan penggunaan data sebesar $17.02 \%$, kesalahan penafsiran bahasa sebesar $19.15 \%$, kesalahan dalam penarikan kesimpulan sebesar sebesar $6.38 \%$, kesalahan penggunaan teorema atau definisi sebesar $17.02 \%$, kesalahan tidak diperiksa kembali sebesar 29.79\%, dan kesalahan dalam perhitungan sebesar $10.64 \%$.

Faktor penyebab terjadinya kesalahan dalam mengerjakan soal trigonometri berdasarkan hasil wawancara ialah siswa tidak tahu menggunakan rumus yang tepat dalam menyelesaikan permasalahan, siswa tidak mengingat rumus, siswa tidak mengulang materi di rumah, siswa tidak memeriksa kembali jawaban, dan siswa tidak memahami untuk menulis kembali informasi dari soal .

Penelitian ini diharapkan dapat menjadi acuan bagi para pendidik juga peneliti dibidang pendidikan, agar dapat memperhatikan cara mengajar dengan menggunakan model dan pendekatan yang lebih tepat sesuai dengan materi dan kondisi siswa pada saat itu, sehingga kesalahan konsep, prosedur, perhitungan, pencarian fakta dan penarikan kesimpulan dapat diminimalisir.

\section{DAFTAR PUSTAKA}

Adhim, B., Amin, S. (2019). Analisis Kesalahan Siswa dalam Menyelesaikan Soal Cerita Materi Limit Trigonometri. MATHEdunesa: Jurnal Ilmiah Pendidikan Matematika, Volume 8 No. 2 Tahun 2019

Akbar, P. Hamid, A. Bernard, M., Sugandi, AI. (2018). Analisis Kemampuan Pemecahan Masalah dan Disposisi Matematik Siswa Kelas XI SMA PUTRA JUANG dalam Materi Peluang. Journal Cendekia: Jurnal Pendidikan Matematika, Volume 2 No. 1, Mei 2018, pp. 144-153. 
Andriani, T., Suastika, K., Sesanti, N. (2017). Analisis Kesalahan Konsep Matematika Siswa dalam Menyelesaikan Saol Trigonometri Kelas X TKJ SMKN 1 Gempol Tahun Pelajaran 2016.2017. Pi:Mathematics Education Journal. Vol. 1 No. 1, Oktober 2017, 34-39.

Andriansyah, R \& Zanthy, L. (2019). Peningkatan Hasil Belajar Menggunakan Pendekatan Problem Solving pada Siswa SMK. Jurnal Pembelajaran Matematika Inovatif, Volume 2, No. 4, juli 2019 Anwar \& Ramdan. (2019). Analisis Kesalahan Siswa Kelas X SMA Negeri 2 Baubau dalam Menyelesaikan Soal Pokok Bahasan Trigonometri. Jurnal Akademik Pendidikan Matematika FKIP Unidayan, Volume 5 - Nomor 1, Mei 2019

Arafani, E., Herlina, E., Zhanty, L, . (2019). Peningkatan Kemampuan Memecahkan Masalah Matematik Siswa SMP dengan Pendekatan Kontekstual. Journal Cendekia: Jurnal Pendidikan Matematika, Volume 03, No. 02, Agustus 2019, pp. 323-332

Baharuddin \& Wahyuni, E. N. (2008). Teori Belajar dan Pembelajaran. Yogyakarta: ARRUZZ MEDIA. Bernard, M., \& Senjayawati, E. (2019). Developing the Students' Ability in Understanding Mathematics and Self-confidence with VBA for Excel. JRAMathEdu (Journal of Research and Advances in Mathematics Education), 1(1), 45-56.

Bernard, M., \& Senjayawati, E. (2019). Meningkatkan Kemampuan Koneksi Matematik Siswa SMP dengan Menggunakan Pendekatan Metaphorical Thinking Berbantuan Software Geogebra. Jurnal Mercumatika: Jurnal Penelitian Matematika dan Pendidikan Matematika, 3(2), 79-87.

Bernard, M., Sumarna, A., Rolina, R., \& Akbar, P. (2019, October). Development of high school student work sheets using VBA for microsoft word trigonometry materials. In Journal of Physics: Conference Series (Vol. 1315, No. 1, p. 012031). IOP Publishing.

Cucu Suhana. (2010). Konsep Strategi Pembelajaran. Bandung: Refika Aditama.

Chotimah, S., Ramdhani, F. A., Bernard, M., \& Akbar, P. (2019). Pengaruh Pendekatan ModelEliciting Activities Terhadap Kemampuan Berpikir Kritis Matematik Siswa Smp Negeri Di Kota Cimahi. Journal on Education, 1(2), 68-77.

Hidayat, F., Akbar, P., \& Bernard, M. (2019). Analisis Kemampuan Berfikir Kritis Matematik Serta Kemandiriaan Belajar Siswa Smp Terhadap Materi Spldv. Journal on Education, 1(2), 515-523. Isnaeni, S., Ansori, A., Akbar, P., \& Bernard, M. (2019). Analisis Kemampuan Koneksi Matematis Siswa Smp Pada Materi Persamaan Dan Pertidaksamaan Linear Satu Variabel. Journal on Education, 1(2), 309-316.

Kariadinata, R. (2012). Trigonometri Dasar. Bandung: CV PUSTAKA SETIA

Niasih, Romlah, S., Zhanty, L. (2019). Analisis Kemampuan Komunikasi Matematis Siswa SMP di Kota Cimahi pada Materi Statistika. Journal Cendekia: Jurnal Pendidikan Matematika, Volume 03, No. 02, Agustus 2019, pp 266-277 
Nurhayati, N., \& Bernard, M. (2019). Analisis Kesulitan Siswa Dalam Pemecahan Masalah Matematik Siswa Kelas X SMK Bina Insan Bangsa Pada Materi Persamaan Dan Pertidaksamaan. Journal on Education, 1(2), 497-502.

Rohaeti, E. E. (2019). Pengembangan Media Visual Basic Application untuk Meningkatkan Kemampuan Penalaran Siswa SMP dengan Pendekatan Open-Ended. SJME (Supremum Journal of Mathematics Education), 3(2), 95-107.

Sugiyono. (2011). Metode Penelitian Kombinasi. Bandung: Alfabeta.

Suhartini, T., Khuzaini, N. (2017). Implementasi Pendekatan Pembelajaran Matematika Realistik Indonesia (PMRI) untuk Meningkatkan Prestasi Belajar Pokok Bahasan Melukis dan Membagi Sudut pada Siswa Kelas VII SMP Negeri 1 Seyegan. Jurnal Mercumatika Vol. 1 No. 2 April 2017 Suyadi. (2011). Manajemen PAUD. Bandung: Remaja Rosdakarya

Warta, N. (2013). Pengembangan Kurikulum Matematika-IPA Terpadu dan Efektivitasnya dalam Pembelajaran untuk Meningkatkan Kemampuan Berpikir Kreatif dan Prestasi Belajar Siswa. ISSN 1829-5282. Hal 42-54

Wiliawanto, W., Bernard, M., Akbar, P., \& Sugandi, A. I. (2019). Penerapan Strategi Pembelajaran Aktif Question Student Have Untuk Meningkatkan Kemampuan Berpikir Kritis Matematik Siswa SMK. Jurnal Cendekia: Jurnal Pendidikan Matematika, 3(1), 139-148.

Zulkardi. (2003). Pendidikan Matematika di Indonesia: Beberapa Permasalahan dan Upaya Penyelesaiannya. Palembang: Unsri 